Recepción: 15/10/2018

Aceptación: 18 /12/2018

Publicación: 20 /01/2019

Ciencias de la educación

\title{
Formación permanente, docentes de la Facultad de Filosofía, Letras y Ciencias de la Educación en la Universidad Técnica de Manabí
}

\section{Permanent training, teachers of the Faculty of Philosophy, Letters and Education Sciences at the Technical University of Manabi}

\section{Formação permanente, docentes da Faculdade de Filosofia, Letras e Ciências da Educação da Universidade Técnica de Manabí}

\section{María Elena Mendoza-Vélez ${ }^{\mathrm{I}}$} mmendozavelez@utm.edu.ec

Gabriela Rossana Guerrero-Aray ${ }^{\text {II }}$ gguerrero@utm.edu.ec

Letty Aracely Delgado-Cedeño III ldelgado@utm.edu.ec

Correspondencia: mmendozavelez@utm.edu.ec 


\section{Resumen}

\section{Palabras clave:}

\section{Abstract}

\section{Key words:}

\section{4}

Pol. Con. (Edición núm. 29) Vol. 4, No 1, enero 2019, pp. 183-194, ISSN: 2550 - 682X 


\section{Resumo}

\section{Palavras-chave:}

\section{Introducción}


Formación permanente, docentes de la Facultad de Filosofía, Letras y Ciencias de la Educación en la Universidad Técnica de Manabí 
Formación permanente, docentes de la Facultad de Filosofía, Letras y Ciencias de la Educación en la Universidad Técnica de Manabí 
Formación permanente, docentes de la Facultad de Filosofía, Letras y Ciencias de la Educación en la Universidad Técnica de Manabí 
Formación permanente, docentes de la Facultad de Filosofía, Letras y Ciencias de la Educación en la Universidad Técnica de Manabí 
